See discussions, stats, and author profiles for this publication at: https://www.researchgate.net/publication/340556976

\title{
Drought and heat wave impacts on grassland carbon cycling across hierarchical levels
}

Article in Plant Cell and Environment · April 2020

Dol: 10.1111/pce.13767

CITATIONS

15 authors, including:

Linfeng Li

Chinese Academy of Sciences

20 PUBLICATIONS 78 CITATIONS

SEE PROFILE

Joel Aaron Biederman

United States Department of Agriculture

59 PUBLICATIONS 1,064 CITATIONS

SEE PROFILE

Some of the authors of this publication are also working on these related projects:

Project the effect of warming and graing on plant $\mathrm{N}$ utility View project

Water and Carbon Cycling in Semiarid Ecosystems View project
Zhen Zhen Zheng

University of Chinese Academy of Science

6 PUBLICATIONS 7 CITATIONS

SEE PROFILE 


\section{Drought and heat wave impacts on grassland carbon cycling across hierarchical}

levels

Running Head: climate extremes effects on carbon cycling

Linfeng Li ${ }^{1,2}$, Zhenzhen Zheng ${ }^{1}$, Joel A. Biederman ${ }^{3}$, Ruyan Qian ${ }^{1}$, Qinwei Ran ${ }^{1}$, Biao Zhang ${ }^{1}$, Cong $\mathrm{Xu}^{1}$, Fang Wang ${ }^{1,2}$, Shutong Zhou ${ }^{1}$, Rongxiao Che ${ }^{4}$, Junfu Dong ${ }^{1}$, Zhihong $\mathrm{Xu}^{2}$, Xiaoyong Cui ${ }^{1,5}$, Yanbin $\mathrm{Hao}^{1,5, *}$ and Yanfen Wang ${ }^{1,5}$

${ }^{1}$ College of Life Sciences, University of Chinese Academy of Sciences, Beijing 100049, China;

${ }^{2}$ Environmental Futures Research Institute, School of Environment and Science, Griffith University, Brisbane 4111, Australia;

${ }^{3}$ Southwest Watershed Research Center, Agricultural Research Service, Tucson, AZ, 85719, USA;

${ }^{4}$ Institude of International Rivers and Eco-security, Yunnan University, Kunming, Yunnan, 650091, China;

${ }^{5}$ CAS Center for Excellence in Tibetan Plateau Earth Sciences, Chinese Academy of Sciences (CAS), Beijing 100101, China.

*Author for correspondence tel +86 1366124 1601; email ybhao@ucas.ac.cn

This article has been accepted for publication and undergone full peer review but has not been through the copyediting, typesetting, pagination and proofreading process which may lead to differences between this version and the Version of Record. Please cite this article as doi: $10.1111 /$ pce.13767 


\begin{abstract}
Droughts and heat waves are increasing in magnitude and frequency, altering the carbon cycle. However, understanding of the underlying response mechanisms remains poor, especially for the combination (hot drought). We conducted a 4-yr. field experiment to examine both individual and interactive effects of drought and heat wave on carbon cycling of a semiarid grassland across individual, functional group, community and ecosystem levels. Drought did not change below-ground biomass (BGB) or aboveground biomass (AGB) due to compensation effects between grass and non-grass functional groups. However, consistently decreased BGB under heat waves limited such compensation effects, resulting in reduced AGB. Ecosystem $\mathrm{CO}_{2}$ fluxes were suppressed by droughts, attributed to stomatal closure-induced reductions in leaf photosynthesis and decreased AGB of grasses, while $\mathrm{CO}_{2}$ fluxes were little affected by heat waves. Overall the hot drought produced the lowest leaf photosynthesis, AGB and ecosystem $\mathrm{CO}_{2}$ fluxes although the interactions between heat wave and drought were usually not significant. Our results highlight that the functional group compensatory effects that maintain community-level AGB rely on feedback of root system responses, and that plant adjustments at the individual level, together with shifts in composition at the functional group level, co-regulate ecosystem carbon sink strength under climate extremes.
\end{abstract}

KEY WORDS: biomass, climate extremes, $\mathrm{CO}_{2}$ flux, compensatory effect, global change, Inner Mongolia, leaf physiology, precipitation 


\section{INTRODUCTION}

Globally, droughts, often in concert with heat waves (i.e. hot drought (Overpeck, 2013)), are the most widespread events affecting terrestrial ecosystem carbon cycling (Reichstein et al., 2013). Hot droughts are likely to occur with increasing frequency and intensity (Easterling, 2000; Stocker, 2014). Although outcomes are highly variable, multiple lines of evidence concur that droughts and heat waves generally cause reductions in ecosystem carbon uptake and productivity (Ciais et al., 2005; Doughty et al., 2015; Hoover, Knapp, \& Smith, 2014; Schwalm et al., 2012; Zhao \& Running, 2010; Zscheischler et al., 2014). Despite significant efforts to understand drought and heat wave impacts, current understanding of the mechanisms behind ecosystem responses to these stressors remains insufficient in multi-model simulations of climate extremes-induced changes in the carbon cycle (Piao et al., 2019). Besides, the interaction between droughts and co-occurring heat waves remains poorly understood (Reichstein et al., 2013; Smith, 2011a).

Droughts and heat waves may cause widespread changes at many levels of the ecological hierarchy spanning the individual, functional group, community and ecosystem levels. Responses at lower hierarchical levels (i.e. individual or community) can have either additive, offsetting or synergistic effects and thus provide mechanisms for higher-levels responses (i.e. ecosystem). Therefore, climate extreme experiments focused on carbon cycling responses across multiple biological scales could significantly improve our understanding of mechanisms underlying carbon cycling responses to climate extremes (Corlett, 2016; Jentsch et al., 2011).

At the individual level, plants may tolerate environmental stress by a variety of physiological or structural adjustments. For example, in order to prevent leaf water potential from falling below a critical level during periods of water stress, plants decrease stomatal conductance, in turn curtailing $\mathrm{CO}_{2}$ uptake (De Boeck, Bassin, 
Verlinden, Zeiter, \& Hiltbrunner, 2016). Additionally, individuals can adapt to water stress by specifically allocating more photosynthate to fine root production in order to increase capacity for water and nutrient uptake, at the expense of leaf production (Burri, Sturm, Prechsl, Knohl, \& Buchmann, 2014; Hasibeder, Fuchslueger, Richter, \& Bahn, 2015; Jaleel et al., 2009). When environmental stress reaches a tipping point beyond an individual plant's threshold tolerance, plant mortality may result (Niu et al., 2014). Response to climate extremes may vary across different functional groups due to various resource-use strategies and threshold tolerances (e.g. $\mathrm{C}_{4}$ vs. $\mathrm{C}_{3}$ functional group in responses to extreme heating event in White, Campbell, Kemp, \& Hunt, 2000; forb vs. grass functional group in responses to extreme droughts in Hoover et al., 2014). As a result, asynchronous or even opposite responses of different functional groups potentially contribute to maintain community-level stability (Bai, Han, Wu, Chen, \& Li, 2004). From a community perspective, such structural changes may entail profound consequences for the ecosystem carbon budget, as plant community structure regulates ecosystem-level $\mathrm{CO}_{2}$ flux responses to climate change (Kuiper, Mooij, Bragazza, \& Robroek, 2014; Ward et al., 2013; Xu et al., 2015). Collectively, physiological and structural processes at the individual level, compositional shifts at the functional group level, and structural changes at the community level, as well as their interactions, culminate in complex ecosystem responses to climate extremes.

There is emerging evidence that droughts and heat waves are often coupled in nature through soil moisture-temperature feedbacks (Ciais et al., 2005; De Boeck \& Verbeeck, 2011; Overpeck, 2013; Seneviratne, Luthi, Litschi, \& Schar, 2006). The expectation is that the negative impacts of drought are intensified by the joint occurrence of higher temperatures (hot drought). However, past manipulative experiments showed high variation in the interactive effects between droughts and high temperatures (De Boeck et al., 2016; Dreesen, De Boeck, Janssens, \& Nijs, 2012; Hoover et al., 2014). 
Compared with a heat wave alone, hot drought is likely to exert a greater influence on ecosystem structure and function (Ciais et al., 2005; De Boeck et al., 2016; De Boeck, Dreesen, Janssens, \& Nijs, 2011), with the outcome related to the combined effects on soil moisture. In contrast, a soil microbial experiment suggested that drought could induce community tolerance to heat waves (Bérard, Sassi, Renault, \& Gros. 2012). In some cases, heat waves combined and droughts unexpectedly triggered additive positive effects on grassland biomass (Dreesen et al., 2012). These heterogeneous responses to the interaction of heat and drought and the unclear mechanisms underlying vegetation responses to these combined stresses highlight that carbon cycle impacts of combined heat waves and droughts remain poorly understood.

To understand how droughts, heat waves and hot droughts affect grassland carbon cycling, we conducted a replicated, factorial manipulative experiment over four years in a semiarid grassland of Inner Mongolia, China. We simultaneously measured key carbon cycle processes at different levels of ecosystem hierarchy to comprehensively examine mechanistic responses, including photosynthetic physiology at the individual level, above-ground biomass (AGB) of grasses, forbs and shrubs at the functional group level, community structure, AGB, below-ground biomass (BGB) and leaf area at the community level, and $\mathrm{CO}_{2}$ fluxes at the ecosystem level. Specifically, we tested the following three hypotheses to single and combined climate extremes: 1) Climate extremes would close stoma or even damage leaves and thereby reduce leaf photosynthetic rate $(A)$ and leaf area index (LAI). Consequently, community-level biomass and ecosystem-level $\mathrm{CO}_{2}$ exchange would be curtailed. 2) Different functional groups (e.g. grass vs. forb vs. shrub) or/and different part of biomass (i.e. AGB vs. BGB) would inconsistently or oppositely respond to climate extremes, which would amplify or buffer the reduction in community-level biomass and ecosystem-level $\mathrm{CO}_{2}$ exchange. 3) Drought would cause larger negative effects than heat waves in semiarid grasslands, 
because drought reduces soil moisture directly and plants often cope with high temperature well, especially when water supply is sufficient (De Boeck et al., 2011; Hoover et al., 2014). Hot drought is expected to have the largest negative effects on all of these, as warming aggravates soil water stress (Ciais et al., 2005; Teskey et al., 2015). 


\section{MATERIALS AND METHODS}

\section{Study site}

This study, as a part of the Extreme Climate Events and Biodiversity-II (ECEB-II) experiment, was conducted at the Inner Mongolia Grassland Ecosystem Research Station in the Xilin River Basin $\left(43^{\circ} 20^{\prime} \mathrm{N}, 116^{\circ} 40^{\prime} \mathrm{E}, 1200 \mathrm{~m}\right.$ a.s.l). The region is characterized by a semiarid continental climate, dry in spring and humid in summer, with a mean annual air temperature $\left(1953\right.$ - 2017) of $2.5^{\circ} \mathrm{C}$ and mean annual precipitation of $281 \mathrm{~mm}$, of which 86\% ( 242 mm) falls during the growing season from May to September. The soil type is classified as dark chestnut in the Chinese soil classification or as Calcis-orthic Aridisol under US Soil Taxonomy classification. The water content is $0.29 \mathrm{~m}^{3} \mathrm{~m}^{-3}$ at field capacity and $0.12 \mathrm{~m}^{3} \mathrm{~m}^{-3}$ at the wilting point (Hao et al., 2010). In 2012, we established the ECEB-II experiment in an undisturbed, native temperate semiarid steppe which has been fenced-off to prevent grazing since 1979. The community is dominated by C3 perennial rhizome and bunch grasses, including Leymus chinensis, Stipa grandis, Achnatherum sibiricum and Agropyron cristatum, which cumulatively account for approximately $75 \%$ of total aboveground biomass.

\section{Experimental design}

In this study, we defined drought by the length of the precipitation-free period. The local precipitation regime is typically centered within the growing season. Thus, we analyzed growing-season weather data (1953-2010, longest record period) obtained from the Meteorological Station of Xilinhot city and found the longest period between two sequential rainfall events was 30 days. We therefore defined an extreme drought treatment as a rain-free period of 30 days. The drought treatments using passive rain exclusion shelters lasted between 20 July and 19 August during mid-growing season each year from 2013 to 2016 . The $99^{\text {th }}$ percentile of daily maximum temperature during 
the growing season is $38^{\circ} \mathrm{C}$, which was used as the cutoff temperature to define a heat wave as per De Boeck, Dreesen, Janssens, \& Nijs (2010). We found just one such event in the historical record. It occurred in July 2000 and lasted 7 days, during which the difference in daily maximum temperature above the historical average was greater $\left(+7.0^{\circ} \mathrm{C}\right)$ than the difference in minimum nighttime temperature $\left(+1.2^{\circ} \mathrm{C}\right)$. Thus, a heat wave in this region is characterized by large increases in daytime temperature with minimal differences at night (Li et al., 2016). Therefore, our heat wave treatment was designed to produce air temperatures of $38{ }^{\circ} \mathrm{C}$ during daytime $(9: 00-15: 00 \mathrm{~h})$ for a period of seven consecutive days, with no nighttime treatment. Warming started from 09:00 a.m., raised the air temperature to around $38 \square$, then maintained this temperature till 15:00. Warming was applied with a transparent infrared lamp (2000 W, 220 V, 100 $\mathrm{cm} \times 31.4 \mathrm{~cm}$, PHILIPS) connected with a thermal resistor (CU 50, Micro Sensor Co., Ltd., China) to an intelligent temperature controller (XMT 7100, Huibang technology Co., Ltd., China).

These two climate extreme factors, drought and heat wave, were crossed to form a fully factorial experiment including four treatments: (1) ambient conditions for control (control), extreme drought (drought), heat wave (heat wave) and drought in combination with heat wave (hot drought). There were three replicates for each treatment and twelve plots $(2.0 \mathrm{~m} \times 2.0 \mathrm{~m}$ each $)$ randomly located in four blocks. Water exchange across plot boundaries was prevented by a metal flashing installed to a depth of $40 \mathrm{~cm}$ and extending $10 \mathrm{~cm}$ above ground. For detailed information about the rainout shelter design and heat wave treatments, see Li et al., (2016).

Due to limited electrical supply at the research site, asynchronous warming was used for heat wave and hot drought treatments. Infrared lamps were moved from heat wave treatment plots to hot drought treatment plots as soon as a heat wave treatment heating finished (for heating periods see Table S1). Ambient environmental conditions during 
the two heating periods were similar each year, as indicated by air and soil temperatures, wind speed and photosynthetically active radiation (Fig. S1). Accordingly, ecosystem $\mathrm{CO}_{2}$ fluxes of the Control treatment were also similar during these two adjacent periods (Fig. S3). Compared with the dynamics observed during the whole vegetative period (about 5 months), these adjacent 7-day periods were quite similar in weather and ecosystem state; therefore, we do not expect ecosystem structure and function responses to climate extremes to be biased by the asynchronous warming.

\section{Micro-climate}

Daily precipitation data were obtained from a nearby (50 m approximately) tipping bucket rain gauge at $1.5 \mathrm{~m}$ above ground (TE525MM, Campbell Scientific Inc.). During the heating period hourly from 9:00 to 15:00, soil temperature at the depth of $10 \mathrm{~cm}$ and canopy temperature at the height of 40-60 cm were measured by soil thermometers (TL-883, Tonglixing technology Co., Ltd., China) and plant canopy thermometers (ST2955, Shanghai Sintek International Trade Co., Ltd., China), respectively. Over the growing season from 2013 to 2016, soil water content (SWC) of the top $20 \mathrm{~cm}$ was measured in each plot with time domain reflectrometry probes (TDR 300, Spectrum Technologies, Inc. CST, USA) vertically inserted into soil. SWC was measured about every 5 days in 2013, 2015 and 2016 and approximately every 10 days in 2014. Soil temperature (Ts) at the depth of $10 \mathrm{~cm}$ and air temperature (Ta) at $50 \mathrm{~cm}$ above the ground were measured manually with thermometers during $\mathrm{CO}_{2}$ flux measurements (see Ecosystem $\mathrm{CO}_{2}$ flux section). To account for any spatial variation (Fig. S2), canopy temperature and SWC were measured in three different locations per plot each measurement, and their mean was used to represent the plot value.

\section{Plant leaf physiology}


We made plant leaf physiological measurements (light-saturated photosynthetic rate $(A)$, stomatal conductance $(g s)$ and chlorophyll fluorescence $(F v / F m)$ ) and leaf temperature ( $\left.\mathrm{T}_{\text {leaf}}\right)$ of the dominant grasses Leymus chinensis, Stipa grandis and Achnatherum sibiricum (this latter species was only measured in the latter two years) during and after experimental treatments from 2013 to 2016 (seven, four, four, and four times, respectively). Among the measurements, $A, g s$ and $T_{\text {leaf }}$ were measured using a portable photosynthesis system (GFS-3000, Heinz Walz GmbH, Effeltrich, Germany) with a 4$\mathrm{cm}^{2}$ leaf cuvette between 9:00 and 11:30 $\mathrm{h}$ in the morning, when ecosystem $\mathrm{CO}_{2}$ fluxes were also measured (see below). One or more fully expanded leaves (paralleled, but not overlapped) per plant per species in each plot was/were placed into the cuvette. Note that curly leaves of S. grandis were directly measured without flattening. Flattening is difficult to perform repeatedly and is unnecessary given our focus on the relative change across treatments. Measurements were performed under saturated light $(1700 \mu \mathrm{mol} \mathrm{m}$ ${ }^{2} \mathrm{~s}^{-1}$ ), while $\mathrm{CO}_{2}$ concentration, block temperature and block humidity were set to ambient conditions. Chlorophyll fluorescence ( $F v / F m$, the maximum quantum efficiency of photosystem II (PS II)), is a widely-used stress indicator, because decreases in dark-adapted $\mathrm{Fv} / \mathrm{Fm}$ reflect damage to PS II. Fv/Fm was recorded using a pulse-amplitude-modulated photosynthesis yield analyzer (Dual-PAM, Heinz Waltz, Effeltrich, Germany) with a leaf clip holder. We tested fluorescence values of fully expanded leaves for each species between 20:00 and 23:00, allowing adequate dark adaptation on the same days when other leaf physiological measurements were made.

\section{Aboveground biomass and community structure}

Aboveground biomass (AGB) and community structure were estimated once a year by harvesting all aboveground plant material in one $0.25-\mathrm{m}^{2}$ quadrat located within each $4-\mathrm{m}^{2}$ plot around 15th September. Before clipping, the number of individuals was 
recorded by species to assess community structure, including richness (number of species in $0.25-\mathrm{m}^{2}$ quadrat), abundance (number of stem per $\mathrm{m}^{2}$ ) and Shannon's diversity $\left(H^{\prime}\right)$. All species were also categorized into three ecological functional groups: grass, forb and shrub. Within four hours of clipping, fresh leaves were separated from the plant and flatted to measure leaf area using a leaf area meter (LI-3000C, LI-COR Inc., Lincoln, NE, USA) and calculate leaf area index (LAI). Then all plant tissues were oven dried at $65{ }^{\circ} \mathrm{C}$ for 48 hours and weighed. For each year, the locations of quadrats were varied to prevent resampling of the same quadrat.

\section{Belowground biomass}

Belowground biomass (BGB) was estimated by specific root length (SRL) and root length (Fischer et al., 2007). SRL at this site was estimated at $36 \mathrm{~m} \mathrm{g-}^{1}$ (Cheng et al., 2016) and root lengths were measured by the minirhizotron technique. In each plot, one transparent minirhizotron tube (7-cm external diameter, 100-cm length) was installed in the soil at a $45^{\circ}$ angle from the horizontal to a depth of $42 \mathrm{~cm}$ during May 2012. Holes were made with a soil corer of the same diameter as the tubes, which ensured tight contact with surrounding soil. Portions of the tubes (20-cm length) exposed at the surface were covered with adhesive aluminum foil, and the ends were capped to prevent entry of water, light, and heat. To quantify root length, images were taken at vertical depths of 0-14 cm, 14-28 cm and 28-42 cm, using a root scanner system (CI-600 Root Growth Monitoring System, CID Inc., Vancouver, WA, USA). Images, taken in grayscale at $400 \mathrm{dpi}$, were analyzed separately using the program RootAnalysis (Analysis Ome Co. Ltd, Beijing, China) to calculate root length. This method has been widely used in many natural multiple-species ecosystems to assess root biomass and we have increased confidence in BGB estimation by this method because it matched BGB based upon traditional soil coring methods in an area adjacent to the experiment 
(Li et al., 2019). We summed AGB and BGB to calculate total biomass (TB).

\section{Ecosystem $\mathrm{CO}_{2}$ flux}

In May 2012, one square stainless steel frame $(50 \mathrm{~cm} \times 50 \mathrm{~cm}, 10 \mathrm{~cm}$ high with $3 \mathrm{~cm}$ extending aboveground) was inserted in each plot. We used an infrared gas analyzer (LI-840A, LI-COR Inc., Lincoln, NE, USA) and a transparent chamber (50 × $50 \times 50$ cm), attached to one air pump (6262-04, LI-COR Inc.) and two plastic pipes, to measure $\mathrm{CO}_{2}$ fluxes between 9:00 - 11:30 h on sunny days (measurement data see Fig. S2). The chamber was successively used without and with a lightproof covering to measure net ecosystem exchange (NEE) and ecosystem respiration (ER), respectively. Each measurement lasted 90 seconds and there was an interval of at least $10 \mathrm{~s}$. between two consecutive recordings to replace the air in the chamber. $\mathrm{CO}_{2}$ flux rates were determined from the time-course of $\mathrm{CO}_{2}$ concentrations (Chen, Lin, Huang, \& Jenerette, 2009). Gross ecosystem production (GEP) was calculated as the difference between NEE and ER. Positive and negative $\mathrm{CO}_{2}$ flux values indicate net ecosystem $\mathrm{CO}_{2}$ emission and uptake, respectively.

\section{Statistical analyses}

We used a repeated measures ANOVA to test for the effects of heat waves, drought, year, and their interactive effects on community biomass (AGB, BGB and TB), community structure (LAI, abundance, richness and Shannon's diversity), annual averaged ecosystem $\mathrm{CO}_{2}$ fluxes (NEE, ER and GEP), and annual averaged plant physiology ( $A$, gs and $F v / F m$ ) for each species. A post-hoc Duncan test was used to test for mean differences of the above variables across the four treatments each year. We also used a paired t-test for heat wave effects on soil temperature and vegetation surface temperature during the heating period. T-tests were also used to determine the 
differences in treatment effects on relative abundance of grass, as well as AGB of grass and non-grass (forb plus shrub) between control and drought/ heat wave/ hot drought. Treatment effects were considered to be statistically significant at $P \leq 0.05$ and marginally significant at $P \leq 0.10$ given the small number of treatment replicates ( $\mathrm{n}=$ 3). All statistical analyses were performed with R v.3.4.4, R (R Core Team, 2018).

We used structural equation modeling (SEM) to quantify the direct and indirect impacts of heat waves and drought on $A$ per species and ecosystem-level net $\mathrm{CO}_{2}$ uptake (-NEE). Drought and heat wave-induced changes in leaf temperature $\left(\mathrm{T}_{\text {leaf }}\right)$, SWC, gs and $F v / F m$ were included in the SEM to explore the effects of climate extremes on $A$. Similarly, several major pathways were constructed to explore the effects of climate extremes on -NEE, including environmental variables (SWC, Ta), A, and LAI, abundance of grass and non-grass, and biomass (AGB of grass and non-grass as well as BGB). Data were fitted to the model using the maximum likelihood estimation method. Adequate model fit was indicated by a non-significant chi-squared test $(P>$ 0.05). SEM analysis was performed using the AMOS 25 software (IBM, SPSS, Armonk, NY, USA). Before SEM analyses were conducted, we first tested for individual relationships between each variable pairing to identify significant and linear relationships (Fig. S3 and S4). 


\section{RESULTS}

\section{Micro-climate}

During the four years of the experiment (2013-2016), rain shelters excluded $49 \mathrm{~mm}, 37$ $\mathrm{mm}, 52 \mathrm{~mm}$ and $42 \mathrm{~mm}$ of ambient precipitation during 30 days of drought treatments, which is equal to $17 \%, 15 \%, 22 \%$ and $22 \%$ of growing season precipitation (GSP) (Fig. 1a-d). The soil water content (SWC) declined clearly during drought periods and recovered rapidly with the first precipitation after drought, while the heat wave treatment did not significantly change SWC (Fig. 1a-d). Heat waves significantly increased the mean canopy temperature by $3.2^{\circ} \mathrm{C}$ and $3.5^{\circ} \mathrm{C}$ during the heating period in heat wave and hot drought treatments, respectively ( $P<0.01$ for both, Fig. 1e-h). Meanwhile, soil temperature was significantly raised by $0.4^{\circ} \mathrm{C}$ and $0.5^{\circ} \mathrm{C}$ in the heat wave and hot drought treatment compared with the ambient control, respectively $(P<$ 0.01 for both, Fig. 1e-h).

\section{Plant physiological responses}

Both drought treatments (drought and hot drought) decreased stomatal conductance (gs) and light-saturated photosynthetic rate (A) over the last three years (but not in 2013), regardless of species and heat wave treatment (Fig. 2 and Table S2). The Fv/Fm values of the three species were $\sim 0.8$ in all treatments across the four years, even though they were significantly and marginally significantly reduced by drought for Leymus chinensis and Stipe grandis, respectively (Figs. 2b, e, h and k, and Table S2). No clear significant heat wave effects were recorded for $g_{S}, A$ and $F v / F m$ over the four years. There were no significant interaction effects between drought and heat wave for these plant physiology parameters in any years, except for the drought and heat wave interaction for Fv/Fm of Stipe grandis (Fig. 2 and Table S2).

Results of SEM suggest that SWC had significant positive effects on $g s$ which further 
had a strongly positive effect on $A$ for all three species. Similarly, SWC had a significant positive effect on $F v / F m$, but $F v / F m$ had significant positive effects on $A$ only for Achnatherum sibiricum. Tleaf had significant or marginally significant negative relationships with SWC and Gs. $\mathrm{T}_{\text {leaf }}$ significantly increased $\mathrm{Fv} / \mathrm{Fm}$ for Leymus chinensis and Stipe grandis but not Achnatherum sibiricum. SWC significantly increased A for Stipe grandis and Achnatherum sibiricum, but not Leymus chinensis. A was significantly increased by $\mathrm{T}_{\text {leaf }}$ and Fv/Fm only for Achnatherum sibiricum (Fig. 3).

\section{Functional group-level responses}

At the functional group-level, we found a decreasing trend of relative abundance of grass in response to all of the climate extreme treatments across the four years, which are evident under the heat wave treatment in year 2014 and under the drought treatment in years 2015 and 2016, except for the hot drought treatment in the first year. Similarly, AGB of grass consistently declined under the heat wave or drought treatments over the first three years, while AGB of non-grass increased. Both AGB of grass and non-grass decreased under the hot drought treatment across the four years and under the separate heat wave and drought treatments in the last year (Fig. 4 and Table S4).

\section{Community-level responses}

At the whole community level, heat waves significantly reduced AGB, BGB and thereby TB, while droughts did not significantly change any component of biomass (Fig. 5 and Table 1). There was a marginally significant two-way interaction between heat wave and year on TB with larger reductions in 2016 than in the other two years, as AGB reduction was mainly reflected in 2016. Interactive effects of drought and heat wave on biomass were not significant. However, the lowest AGB was usually found in the hot drought treatment (Fig. 5 and Table 1). Overall, climate extremes had little 
effects on the whole community-level structure (LAI, abundance, richness and Shannon’s diversity ( $\left.H^{\prime}\right)$, Fig. S5 and Table S3).

\section{Ecosystem $\mathrm{CO}_{2}$ fluxes}

Droughts significantly suppressed growing season average ecosystem $\mathrm{CO}_{2}$ fluxes (NEE, ER and GEP) across the four years, and such effect was smaller in 2015 than the other three years (drought $\times$ year interaction, $P=0.03$ and 0.08 for NEE and GEP, respectively; Fig. 6, Fig. S6 and Table 1). Heat waves had no significant effects on any growing season average $\mathrm{CO}_{2}$ fluxes, whereas there was a marginally significant positive effect on NEE ( $P=0.07$, Fig. 6, Fig. S2 and Table 1$)$. Across all $\mathrm{CO}_{2}$ fluxes, there were no significant two-way interactions between drought and heat wave, nor three-way interactions among drought, heat wave and year; however, the magnitude of $\mathrm{CO}_{2}$ fluxes were generally the lowest in the hot drought treatment (Fig. 6).

Results of SEM suggest that SWC had positive effects on A, LAI and grass abundance. LAI and grass abundance further had positive effects on AGB of grass. A and AGB of grass had positive effects on ecosystem $\mathrm{CO}_{2}$ uptake. Air temperature (Ta) had no significant effects on other variables (Fig. 7). 


\section{DISCUSSION}

It has long been recognized that carbon cycling processes in semiarid grasslands are highly sensitive to climate change (Christensen, Coughenour, Ellis, \& Chen, 2004; Biederman et al., 2017). Here we conducted a full factorial manipulative experiment to test single and especially interaction of climate extremes, which is more meaningful and powerful in predicting global change effects than single-factor studies (Luo et al., 2008; Zhu, Chiariello, Tobeck, Fukami, \& Field, 2016). Importantly, we measured physical and biological responses across multiple levels of ecological hierarchy simultaneously, allowing us to identify comprehensive mechanisms of grassland carbon cycle response to heat wave and drought.

\section{Drought impacts on grassland carbon cycling across hierarchical levels}

Overall, drought reduced stomatal conductance and leaf photosynthetic rate of all three dominant grass species, Leymus chinensis, Stipe grandis and Achnatherum sibiricum (Table S2), partly supporting our first hypothesis that reduced soil water content would have a negative effect on stomatal conductance, reducing leaf photosynthetic rate (Fig. 2). Our results are in accordance with other drought studies showing that plants may respond to water deficit by closing their stomata to prevent water loss, consequently curtailing leaf photosynthetic rate due to reductions of $\mathrm{CO}_{2}$ diffusion from air into leaf (Asensio, Penuelas, Ogaya, \& Llusia, 2007; Erice et al., 2011). However, drought did not reduce chlorophyll fluorescence (around 0.8, Fig. 2), the optimal value of which is about 0.83 for most non-stressed plant species (Björkman \& Demmig, 1987). Our results suggest that immediate but transient stomatal closure allowed plants to tolerate the water stress without permanent leaf damage.

Decreased leaf photosynthesis of grasses led to reductions in AGB of grasses fuctional group under drought. Additionally, relative abundance of grass was generally reduced 
in the face of drought (Fig. 4b). It means grass functional group is vulnerable to drought in this simiarid grassland. However, community-level AGB was not significantly reduced by drought (Fig. 5a), which was attributed to the fact that AGB and relative abundance of non-grass functional group were increased at the same time (Fig. 4b). This may be because many shrub and forb species in this grassland, such as Artemisia frigida, Potentilla acaulis and Carex, are characterized by drought tolerance or/and strong colonization ability (Y. Gao et al., 2009; Y. Z. Gao et al., 2007). Such compensatory effects among major components at the functional group levels buffered the effects of climate inter-annual and seasonal variability on community-level structure and biomass in this mature grassland with high species richness and community biodiversity (Bai et al., 2004; Liu et al., 2017).

In addition to biomass, whole community-level structure was stable in the face of drought (Fig. S5 b, c, and d). Taken together, our results suggest aboveground components of this semiarid grassland were resistant to the drought of $\sim 60$-year recurrence interval. The minor changes in community structure and AGB under droughts in this study might also partly result from feedbacks of root system response. There was a slight non-significant increasing trend of BGB in the drought treatment (Fig. 5), possibly due to plant structural adaptive strategies in response to water stress; that is, drought stimulated translocation of newly assimilated carbon from shoot to root (Burri et al., 2014; Huang \& Fu, 2000; Sanaullah, Chabbi, Rumpel, \& Kuzyakov, 2012) to increase the potential for water and nutrient uptake (van der Molen et al., 2011). Stronger root systems in turn promote resistance of aboveground parts to climate stress.

SEM results suggest that decreases in leaf photosynthesis and AGB of grass via LAI and grass abundance under drought made large contribution to reduced net carbon uptake at the ecosystem level in this semiarid ecosystem (Fig. 6 and 7). As we hypothesized, ecosystem $\mathrm{CO}_{2}$ uptake in response to water stress was strongly regulated 
by photosynthesis at the individual level (Fig. 7), as $\mathrm{CO}_{2}$ uptake directly achieved by this metabolic process. Individual photosynthesis was mainly controlled by stomatal conductance (Fig. 3), indicating stomatal conductance is a powerful proxy for ecosystem $\mathrm{CO}_{2}$ uptake.

Prior manipulative experiments in this grassland have demonstrated that LAI has a positive relationship with carbon uptake in the face of precipitation changes at the ecosystem scale (Liu et al., 2017). A multiple-model study at this site suggested that inter-annual variability of GEP was attributed to responses of $A$ and LAI to soil water (Hu et al., 2018). Our SEM results provide an insight into positive effects of LAI on ecosystem $\mathrm{CO}_{2}$ uptake and suggest that LAI regulated $\mathrm{CO}_{2}$ uptake through AGB of grasses, but not of forbs and shrubs (Fig. 7). Besides, grass abundance could also exert positive effects on ecosystem $\mathrm{CO}_{2}$ uptake via AGB of grass, while non-grass abundance had no significant effects. It highlights the key and important role of grass in controlling ecosystem $\mathrm{CO}_{2}$ uptake, consistent with vegetation removal experiments showing that the greatest decrease in $\mathrm{CO}_{2}$ sink strength after warming when grasses were present in peatlands (Ward et al., 2013) and that grass removal lead to larger losses in $\mathrm{CO}_{2}$ sink than shrub removal under drought (Kuiper et al., 2014).

\section{Heat wave impacts on grassland carbon cycling across hierarchical levels}

Heat wave did not affect chlorophyll fluorescence while slightly decreased leaf photosynthetic rates for all the species (Fig. 2), consistent with the negative relationship between leaf temperature and stomatal conductance (Fig. 3). Our results suggest that photosynthesis may remain resistant to temperatures as high as $38{ }^{\circ} \mathrm{C}$ in the dominant species of this long-term fenced semiarid grassland.

Similar to drought, functional group compensation, decreasing grass and increasing non-grass biomass, was also found under heat wave during the first three years (Fig. 
4a), maintaining the community-level AGB largely unchanged. However, a negative AGB response was measured in the fourth year, when AGB of grass and non-grass declined together (Fig. 5a). We suggest the AGB compensatory effects disappeared because of the cumulative negative effects of four years of heat waves on root production, limiting nutrient and water uptake and ultimately aboveground growth (Fig. 5b). Reduced AGB in the fourth year advances understanding from prior, shorter-term manipulative heat wave experiments showing AGB is little affected after 1-2 years heat wave treatment, especially when soil moisture remains sufficient (De Boeck et al., 2011; De Boeck et al., 2016; Dreesen et al., 2012; Hoover et al., 2014). It is unknown whether reductions in BGB was prevalent in these prior heat wave studies, because it was not measured. It is also unclear whether the observed unchanged AGB in prior short-term heat wave experiments would have shown declines after additional years.

Our results that community-level biomass both aboveground and belowground were significantly reduced in response to heat wave (Fig. 5), in agreement with another heat wave experiment suggesting that a 7-day heat wave of $+12{ }^{\circ} \mathrm{C}$ above ambient decreased leaf, stem and root biomass (Bauweraerts et al., 2014). However, a recent meta-analysis suggested that experimental warming stimulates grassland aboveground and belowground primary productivity (Wang et al., 2019). Large reductions in BGB dominated the negative response of total biomass (TB), also contrasting with past findings that long-term climate warming shifted TB allocation belowground (Liu et al., 2018). These results hightlight discrepant effects of long-term "press” warming and short-term "pulse” heat waves on grassland biomass.

\section{Combined drought and heat wave impacts on grassland carbon cycling across hierarchical levels}

Contrary to our third hypothesis, the interactions of drought and heat wave on 
ecosystem carbon cycling were not significant at any hierarchal level, regardless of timing of hot drought treatment (Table 1, S5 and S6). A potential limitation with respect to our examination of interactions was asynchronous warming for heat wave and hot drought treatments due to limited electrical supply at the research site. Fortunately, in the absence of large fluctuation in ambient environmental conditions during the two heating periods each year made the four treatments comparable to a large extent. Additionally, direct comparison of drought with hot drought treatment showed key states and fluxes of the hot drought treatment (e.g. A, AGB, NEE, ER, and GEP), just non-significantly lower than those of the drought treatment alone. Therefore, we are confident that there were not significant interactions of drought and heat wave in this study.

In contrast to the single drought or heat wave treatment, we did not find compensatory effects between grass and non-grass functional groups under the hot drought treatment. Instead, AGB of both grass and non-grass were consistently reduced across the four years (Fig. 4c). Hot drought plots had the lowest AGB of all treatments in each year, although the interactions of heat wave and drought were not significant (Fig. 5a). It is because root production was reduced, similar to the heat wave treatment (Fig. 5b), curtailing capacity for water and nutrition uptake as mentioned above. Importantly, soil water content was lower under the hot drought treatment than the heat wave treatment alone, further limiting transportation of water and nutrition to aboveground plant parts. Consequently, the compensatory effects of plant functional groups which initially maintained AGB under the hot drought treatment disappeared after the first year.

Although the interactions of drought and heat wave on ecosystem $\mathrm{CO}_{2}$ fluxes were not significant, the hot drought treatment had the lowest magnitudes of NEE, ER and GEP in each year (Fig. 6), suggesting apparent additive negative effects. This non- 
significance of interaction may be because the heat wave did not cause significant effects on soil moisture as compared with the drought alone (Fig. 1). The additive negative effects of drought and heat wave on ecosystem $\mathrm{CO}_{2}$ exchange could result from negative effects of leaf temperature on stomatal conductance and thereby leaf photosynthetic rates (Fig. 1e-h and 3) as well as larger reduction in AGB of grass (Fig. 5c).

This study has direct implications for understanding of grassland structure and functions amid future climate changes. By connecting responses across multiple hierarchal levels, we can provide a more comprehensive mechanism behind carbon cycle response to climate extremes than past "patch" studies. Our findings indicate that individual physiological adjustments controlled photosynthesis responses, and then drove corresponding species biomass responses, ultimately co-regulating ecosystem carbon exchange. Meanwhile, individual structural adjustments and compensation effects between functional groups co-determined total biomass response. 


\section{Acknowledgements}

This project was funded by the CAS Strategic Priority Research Programme (A) (Grant No. XDA20050103, XDA19030202) and the International Cooperation and Exchange of National Natural Science Foundation of China (Grant No. 31761123001, 31761143018). Great thanks for the help of the Inner Mongolia Grassland Ecosystem Research Station. 


\section{Conflict of Interest statement}

There is no conflict of interest to declare.

This article is protected by copyright. All rights reserved. 


\section{References}

Asensio, D., Penuelas, J., Ogaya, R., \& Llusia, J. (2007). Seasonal soil and leaf $\mathrm{CO}_{2}$ exchange rates in a Mediterranean holm oak forest and their responses to drought conditions. Atmospheric Environment, 41(11), 2447-2455.

Bai, Y. F., Han, X. G., Wu, J. G., Chen, Z. Z., \& Li, L. H. (2004). Ecosystem stability and compensatory effects in the Inner Mongolia grassland. Nature, 431(7005), 181-184.

Bauweraerts, I., Ameye, M., Wertin, T. M., McGuire, M. A., Teskey, R. O., \& Steppe, K. (2014). Water availability is the decisive factor for the growth of two tree species in the occurrence of consecutive heat waves. Agricultural and Forest Meteorology, 189-190, 19-29.

Biederman, J. A., Scott, R. L., Bell, T. W., Bowling, D. R., Dore, S., Garatuza $\square$ Payan, J., . . . Litvak, M. E. (2017). $\mathrm{CO}_{2}$ exchange and evapotranspiration across dryland ecosystems of southwestern North America. Global Change Biology, 23(10), 4204-4221.

Bérard, A., Sassi M., Renault P., \& Gros R. (2012). Severe drought-induced community tolerance to heat wave. An experimental study on soil microbial processes. Journal of Soils and Sediments 12,513-518.

Björkman, O., \& Demmig, B. (1987). Photon yield of $\mathrm{O}_{2}$ evolution and chlorophyll fluorescence characteristics at $77 \mathrm{~K}$ among vascular plants of diverse origins. Planta, 170(4), 489-504.

Burri, S., Sturm, P., Prechsl, U. E., Knohl, A., \& Buchmann, N. (2014). The impact of extreme summer drought on the short-term carbon coupling of photosynthesis to soil $\mathrm{CO}_{2}$ efflux in a temperate grassland. Biogeosciences, 11(4), 961-975.

Chen, S., Lin, G., Huang, J., \& Jenerette, G. D. (2009). Dependence of carbon sequestration on the differential responses of ecosystem photosynthesis and 
respiration to rain pulses in a semiarid steppe. Global Change Biology, 15(10), 2450-2461.

Cheng, J., Chu, P., Chen, D., Bai, Y., \& Niu, S. (2016). Functional correlations between specific leaf area and specific root length along a regional environmental gradient in Inner Mongolia grasslands. Functional Ecology, 30(6), 985-997.

Christensen, L., Coughenour, M. B., Ellis, J. E., \& Chen, Z. Z. (2004). Vulnerability of the Asian typical steppe to grazing and climate change. Climatic Change, 63(3), 351-368.

Ciais, P., Reichstein, M., Viovy, N., Granier, A., Ogee, J., Allard, V., . . . Valentini, R. (2005). Europe-wide reduction in primary productivity caused by the heat and drought in 2003. Nature, 437(7058), 529-533.

Corlett, R. T. (2016). The Impacts of Droughts in Tropical Forests. Trends in Plant Science, 21(7), 584-593.

De Boeck, H. J., Bassin, S., Verlinden, M., Zeiter, M., \& Hiltbrunner, E. (2016). Simulated heat waves affected alpine grassland only in combination with drought. New Phytologist, 209(2), 531-541.

De Boeck, H. J., Dreesen, F. E., Janssens, I. A., \& Nijs, I. (2010). Climatic characteristics of heat waves and their simulation in plant experiments. Global Change Biology, 16(7), 1992-2000.

De Boeck, H. J., Dreesen, F. E., Janssens, I. A., \& Nijs, I. (2011). Whole-system responses of experimental plant communities to climate extremes imposed in different seasons. New Phytologist, 189(3), 806-817.

De Boeck, H. J., \& Verbeeck, H. (2011). Drought-associated changes in climate and their relevance for ecosystem experiments and models. Biogeosciences, 8(5), $1121-1130$.

Doughty, C. E., Metcalfe, D. B., Girardin, C. A., Amezquita, F. F., Cabrera, D. G., 
Huasco, W. H., . . Malhi, Y. (2015). Drought impact on forest carbon dynamics and fluxes in Amazonia. Nature, 519(7541), 78-82.

Dreesen, F. E., De Boeck, H. J., Janssens, I. A., \& Nijs, I. (2012). Summer heat and drought extremes trigger unexpected changes in productivity of a temperate annual/biannual plant community. Environmental and Experimental Botany, 79, 21-30. doi:10.1016/j.envexpbot.2012.01.005

Easterling, D. R. (2000). Climate Extremes: Observations, Modeling, and Impacts. Science, 289(5487), 2068-2074.

Erice, G., Louahlia, S., Irigoyen, J. J., Sánchez-Díaz, M., Alami, I. T., \& Avice, J.-C. (2011). Water use efficiency, transpiration and net $\mathrm{CO}_{2}$ exchange of four alfalfa genotypes submitted to progressive drought and subsequent recovery. Environmental and Experimental Botany, 72(2), 123-130.

Fischer, D. G., Hart, S. C., LeRoy, C. J., \& Whitham, T. G. (2007). Variation in belowground carbon fluxes along a Populus hybridization gradient. New Phytologist, 176(2), 415-425.

Gao Y., Giese M., Han X., Wang D., Zhou Z., Brueck H., ... Taube F. (2009). Land use and drought interactively affect interspecific competition and species diversity at the local scale in a semiarid steppe ecosystem. Ecological research 24(3), 627-635.

Gao Y., Wang S., Han X., Chen Q., Zhou Z., Patton B. (2007). Defoliation, nitrogen, and competition: effects on plant growth and resource allocation of Cleistogenes squarrosa and Artemisia frigida. Journal of Plant Nutrition and Soil Science 170(1), 115-122.

Hao, Y., Wang, Y., Mei, X., Cui, X., Zhou, X., \& Huang, X. (2010). The sensitivity of temperate steppe $\mathrm{CO}_{2}$ exchange to the quantity and timing of natural interannual rainfall. Ecological Informatics, 5(3), 222-228. 
Hasibeder, R., Fuchslueger, L., Richter, A., \& Bahn, M. (2015). Summer drought alters carbon allocation to roots and root respiration in mountain grassland. New Phytologist, 205(3), 1117-1127.

Hoover, D. L., Knapp, A. K., \& Smith, M. D. (2014). Resistance and resilience of a grassland ecosystem to climate extremes. Ecology, 95(9), 2646-2656.

Hu, Z., Shi, H., Cheng, K., Wang, Y. P., Piao, S., Li, Y., .. Y Yu, G. (2018). Joint structural and physiological control on the interannual variation in productivity in a temperate grassland: A data-model comparison. Global Chang Biology, 24(7), 2965-2979.

Huang, B., \& Fu, J. (2000). Photosynthesis, respiration, and carbon allocation of two cool-season perennial grasses in response to surface soil drying. Plant and Soil, 227(1-2), 17-26.

Jaleel, C. A., Manivannan, P., Wahid, A., Farooq, M., Al-Juburi, H. J., Somasundaram, R., \& Panneerselvam, R. (2009). Drought stress in plants: a review on morphological characteristics and pigments composition. International Journal of Agriculture Biology, 11(1), 100-105.

Jentsch, A., Kreyling, J., Elmer, M., Gellesch, E., Glaser, B., Grant, K., . . . Beierkuhnlein, C. (2011). Climate extremes initiate ecosystem-regulating functions while maintaining productivity. Journal of Ecology, 99(3), 689-702.

Kuiper, J. J., Mooij, W. M., Bragazza, L., \& Robroek, B. J. M. (2014). Plant functional types define magnitude of drought response in peatland $\mathrm{CO}_{2}$ exchange. Ecology, 95(1), 123-131.

Li, L., Fan, W., Kang, X., Wang, Y., Cui, X., Xu, C., . . Hao, Y. (2016). Responses of greenhouse gas fluxes to climate extremes in a semiarid grassland. Atmospheric Environment, 142, 32-42.

Li L., Zheng Z., Biederman J., Xu C., Xu Z., Che R., ... Hao Y. (2019). Ecological 
responses to heavy rainfall depend on seasonal timing and multi $\square$ year recurrence. New Phytologist, 223, 647-660.

Liu, H., Mi, Z., Lin, L., Wang, Y., Zhang, Z., Zhang, F., . . . He, J. S. (2018). Shifting plant species composition in response to climate change stabilizes grassland primary production. Proceedings of the National Academy of Science, 115(16), 4051-4056.

Liu, W. J., Li, L. F., Biederman, J. A., Hao, Y. B., Zhang, H., Kang, X. M., . . X Xu, C. Y. (2017). Repackaging precipitation into fewer, larger storms reduces ecosystem exchanges of $\mathrm{CO}_{2}$ and $\mathrm{H}_{2} \mathrm{O}$ in a semiarid steppe. Agricultural and Forest Meteorology, 247, 356-364.

Luo, Y., Gerten, D., Le Maire, G., Parton, W. J., Weng, E., Zhou, X., . . Rustad, L. (2008). Modeled interactive effects of precipitation, temperature, and $\mathrm{CO}_{2}$ on ecosystem carbon and water dynamics in different climatic zones. Global Change Biology, 14(9), 1986-1999.

Niu, S., Luo, Y., Li, D., Cao, S., Xia, J., Li, J., \& Smith, M. D. (2014). Plant growth and mortality under climatic extremes: An overview. Environmental and Experimental Botany, 98, 13-19.

Overpeck, J. T. (2013). Climate science: The challenge of hot drought. Nature, 503(7476), 350.

Piao, S., Zhang, X., Chen, A., Liu, Q., Lian, X., Wang, X., . . . Wu, X. (2019). The impacts of climate extremes on the terrestrial carbon cycle: A review. Science China Earth Sciences, 62(10), 1551-1563.

R Core Team. 2018. R: a language and environment for statistical computing. Vienna, Austria: R Foundation for Statistical Computing. [WWW document] URL https://www.r-project.org/.

Reichstein, M., Bahn, M., Ciais, P., Frank, D., Mahecha, M. D., Seneviratne, S. I., . . . 
Wattenbach, M. (2013). Climate extremes and the carbon cycle. Nature, 500(7462), 287-295.

Sanaullah, M., Chabbi, A., Rumpel, C., \& Kuzyakov, Y. (2012). Carbon allocation in grassland communities under drought stress followed by ${ }^{14} \mathrm{C}$ pulse labeling. Soil Biology and Biochemistry, 55, 132-139.

Schwalm, C. R., Williams, C. A., Schaefer, K., Baldocchi, D., Black, T. A., Goldstein, A. H., . . S Scott, R. L. (2012). Reduction in carbon uptake during turn of the century drought in western North America. Nature Geoscience, 5(8), 551-556.

Seneviratne, S. I., Luthi, D., Litschi, M., \& Schar, C. (2006). Land-atmosphere coupling and climate change in Europe. Nature, 443(7108), 205-209.

Smith, M. D. (2011a). An ecological perspective on extreme climatic events: a synthetic definition and framework to guide future research. Journal of Ecology, 99(3), 656-663.

Stocker, T. (2014). Climate change 2013: the physical science basis: Working Group I contribution to the Fifth assessment report of the Intergovernmental Panel on Climate Change: Cambridge University Press.

Teskey, R., Wertin, T., Bauweraerts, I., Ameye, M., McGuire, M. A., \& Steppe, K. (2015). Responses of tree species to heat waves and extreme heat events. Plant, Cell \& Environment, 38(9), 1699-1712.

van der Molen, M. K., Dolman, A. J., Ciais, P., Eglin, T., Gobron, N., Law, B. E., . . . Wang, G. (2011). Drought and ecosystem carbon cycling. Agricultural and Forest Meteorology, 151(7), 765-773.

Wang, N., Quesada, B., Xia, L., Butterbach-Bahl, K., Goodale, C. L., \& Kiese, R. (2019). Effects of climate warming on carbon fluxes in grasslands- A global meta-analysis. Global Change Biology, 25(5), 1839-1851.

Ward, S. E., Ostle, N. J., Oakley, S., Quirk, H., Henrys, P. A., \& Bardgett, R. D. (2013). 
Warming effects on greenhouse gas fluxes in peatlands are modulated by vegetation composition. Ecology Letters, 16(10), 1285-1293.

White, T. A., Campbell, B. D., Kemp, P. D., \& Hunt, C. L. (2000). Sensitivity of three grassland communities to simulated extreme temperature and rainfall events. Global Change Biology, 6(6), 671-684.

Xu, X., Shi, Z., Li, D., Zhou, X., Sherry, R. A., \& Luo, Y. (2015). Plant community structure regulates responses of prairie soil respiration to decadal experimental warming. Global Chang Biology, 21(10), 3846-3853.

Zhao, M., \& Running, S. W. (2010). Drought-induced reduction in global terrestrial net primary production from 2000 through 2009. Science, 329(5994), 940-943.

Zhu, K., Chiariello, N. R., Tobeck, T., Fukami, T., \& Field, C. B. (2016). Nonlinear, interacting responses to climate limit grassland production under global change. Proceedings of the National Academy of Sciences, 113(38), 10589-10594.

Zscheischler, J., Michalak, A. M., Schwalm, C., Mahecha, M. D., Huntzinger, D. N., Reichstein, M., .. . Zeng, N. (2014). Impact of large-scale climate extremes on biospheric carbon fluxes: An intercomparison based on MsTMIP data. Global Biogeochemical Cycles, 28(6), 585-600. 
Table 1. Results of repeated ANOVA for responses of aboveground biomass (AGB), belowground biomass (BGB), total biomass (TB), net ecosystem exchange (NEE), ecosystem respiration (ER), and gross ecosystem production (GEP) to drought, heat wave, year, and their interactions.

\begin{tabular}{lllllll}
\hline & AGB & BGB & TB & NEE & ER & GEP \\
\hline Heat wave & $\mathbf{0 . 0 5}$ & $\mathbf{0 . 0 1}$ & $<\mathbf{0 . 0 1}$ & 0.07 & 0.81 & 0.13 \\
Drought & 0.31 & 0.34 & 0.40 & $<\mathbf{0 . 0 1}$ & $<\mathbf{0 . 0 1}$ & $<\mathbf{0 . 0 1}$ \\
Year & $<\mathbf{0 . 0 1}$ & 0.68 & 0.17 & $<\mathbf{0 . 0 1}$ & $<\mathbf{0 . 0 1}$ & $<\mathbf{0 . 0 1}$ \\
Heat wave $\times$ Drought & 0.48 & 0.71 & 0.68 & 0.73 & 0.99 & 0.79 \\
Heat wave $\times$ Year & 0.68 & 0.06 & 0.07 & 0.91 & 0.84 & 0.89 \\
Drought $\times$ Year & 0.79 & 0.80 & 0.70 & $\mathbf{0 . 0 3}$ & 0.59 & 0.08 \\
Heat wave $\times$ Drought $\times$ Year & 0.56 & 0.34 & 0.37 & 0.93 & 0.42 & 0.93 \\
\hline
\end{tabular}

$P$-values in bold are statistically significant to an alpha value of 0.05 . 


\section{Figures Legends}

Fig. 1. Precipitation and soil water content during the growing season (a-d) and heating effects on soil and canopy temperature during the heating periods (e-h). $\Delta$ Temperature is the difference between heating treatments and control treatment. The blue, orange and green shaded stripes in a-d indicate periods of drought treatment, and periods of heating in heat wave and hot drought treatments, respectively. Error bars indicate 1 SE.

Fig. 2. Climate extremes effects on leaf physiologies of the three dominant species. gs: stomatal conductance; Fv/Fm: chlorophyll fluorescence; and A: leaf photosynthetic rate. Error bars indicate 1 SE. Different letters indicate significant differences $(P \leq 0.05)$ among treatments.

Fig. 3. Structural equation model showing the effects of abiotic factors and biotic factors on plant leaf photosynthesis. $T_{\text {leaf: }}$ leaf surface temperature, SWC: soil water content, gs: stomatal conductance, Fv/Fm: chlorophyll fluorescence, and A: leaf photosynthetic rate. Solid black and solid grey arrows represent significant $(P \leq 0.05)$ or marginally significant $(0.05<P<0.10)$ paths for all there species, for only two species, respectively, while grey dashed arrows represent significant $(P \leq 0.05)$ paths for only one species. Standardized path coefficients are listed on each path (three numbers for Leymus chinensis, Stipe grandis and Achnatherum sibiricum successively), in which, black indicates significant, grey indicates marginally significant while ns indicate non-significant $(P \geq 0.10) . r^{2}$ values represent the proportion of variance explained for each variable. Column graph in below panel showing the standardized total effects (sum of direct and indirect effects) derived from the structural equation model.

Fig. 4. Climate extremes effects on aboveground biomass of grass and non-grass and relative abundance of grass. $\Delta$ is the difference of treatment and control. Error bars indicate $1 \mathrm{SE}$. Asterisks are significant at different levels between treatments and 
control: $* P<0.10, * * P<0.05$.

Fig. 5. Climate extremes effects on community biomass. AGB: aboveground biomass; BGB: belowground biomass; and TB: total biomass. Error bars indicate 1 SE. Different letters indicate significant differences $(P \leq 0.05)$ among treatments while ns indicates no significant difference among treatments.

Fig. 6. Climate extremes effects on ecosystem $\mathrm{CO}_{2}$ fluxes. Solid column and empty column in upper half represent ecosystem respiration (ER) and gross ecosystem production (GEP), respectively, while solid column in bottom half represents net ecosystem exchange (NEE). Negative values indicate the ecosystem absorbs $\mathrm{CO}_{2}$ from the atmosphere (net sink), while positive values indicate the ecosystem emits $\mathrm{CO}_{2}$ into the atmosphere (net source). Error bars indicate 1 SE. Different letters indicate significant differences $(P \leq 0.05)$ among treatment.

Fig. 7. Structural equation model showing the effects of abiotic factors and biotic factors on net ecosystem $\mathrm{CO}_{2}$ uptake. SWC: soil water content, Ta: air temperature, $A$ : leaf photosynthetic rate; LAI: leaf area index. Abundancegrass and Abundcane ${ }_{\text {non-grass }}$ indicate abundance of grass and non-grass (forb plus shrub), respectively. AGB grass $_{\text {and }}$ and $\mathrm{AGB}_{\text {non-grass }}$ indicate aboveground biomass of grass and non-grass, respectively. BGB: belowground biomass. Ecosystem $\mathrm{CO}_{2}$ uptake is absolute value of net ecosystem exchange (NEE). $r^{2}$ values represent the proportion of variance explained for each variable. Solid and dashed arrows represent significant $(P \leq 0.05)$ and non-significant $(P>0.05)$ paths, respectively. Standardized path coefficients are listed on each path. Column graph in left bottom showing the standardized total effects (sum of direct and indirect effects) derived from the structural equation model. 
- It is indispensable to explore the mechanisms and impacts of climate extremes on the carbon cycle given they are increasing in magnitude and frequency.

- Aboveground biomass responses to climate extremes rely on the functional group compensatory effects and feedbacks of root system responses.

- Plant physiological adjustments and shifts in community composition co-regulate ecosystem $\mathrm{CO}_{2}$ fluxes under climate extremes. 

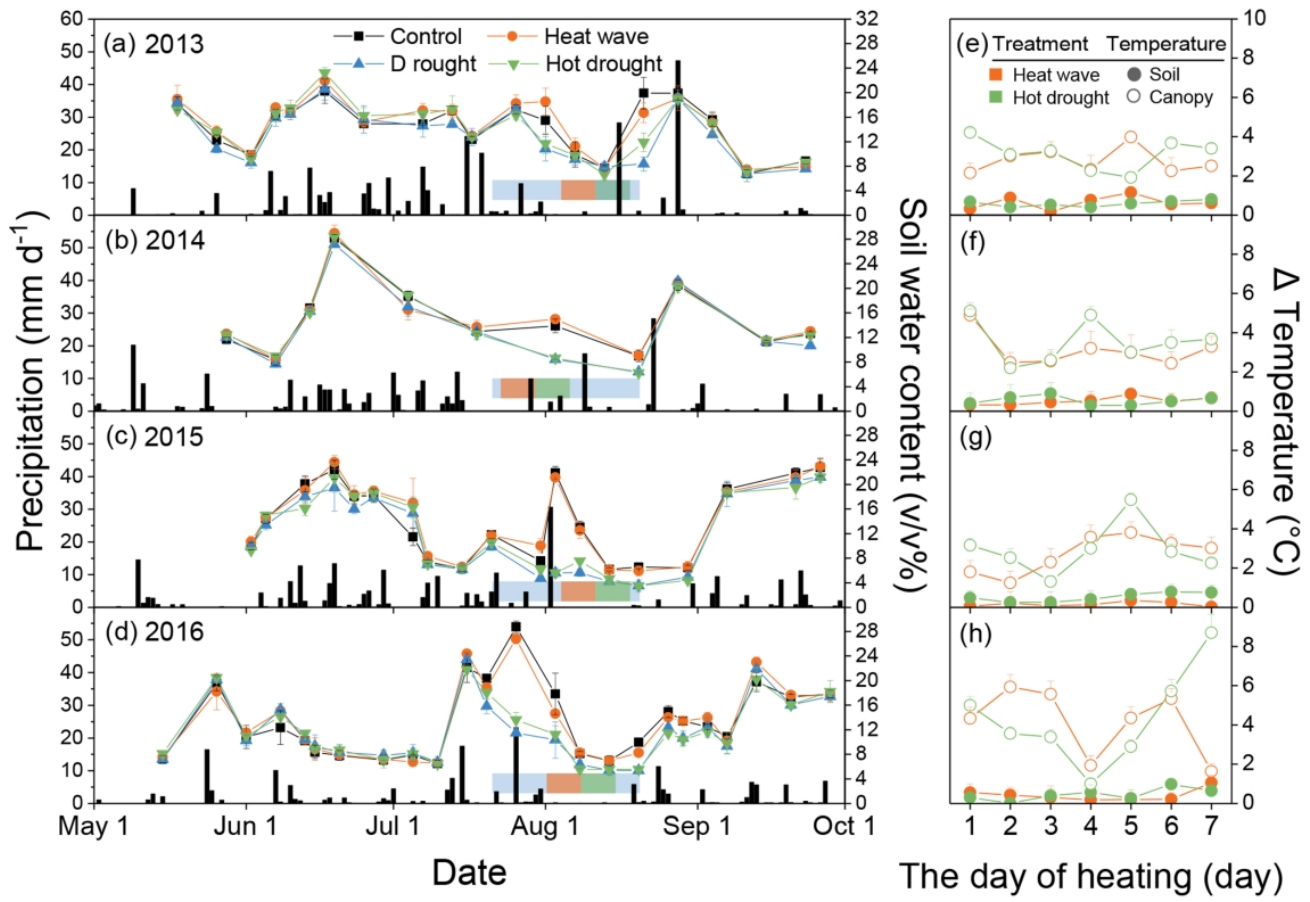

This article is protected by copyright. All rights reserved. 

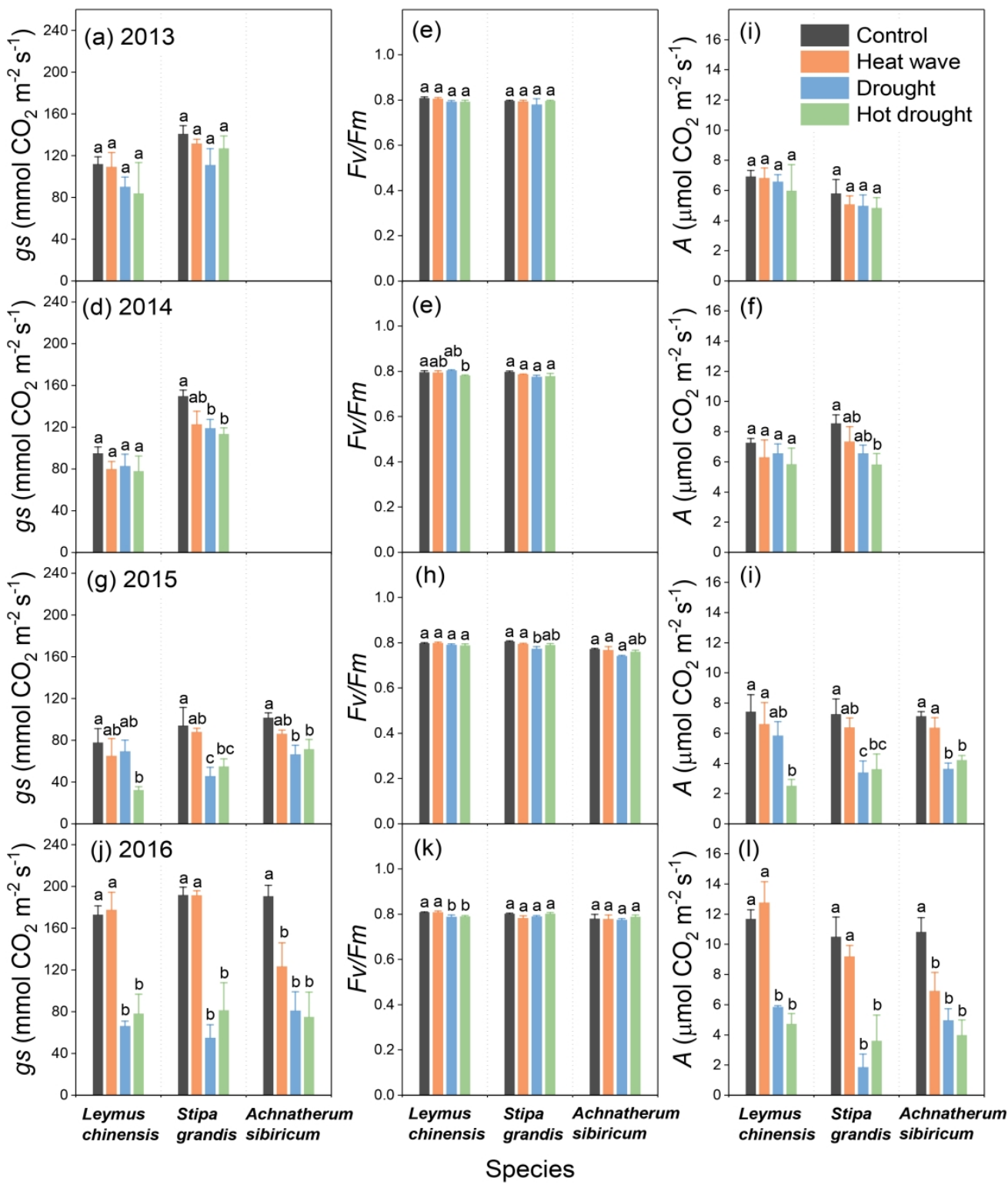

This article is protected by copyright. All rights reserved. 

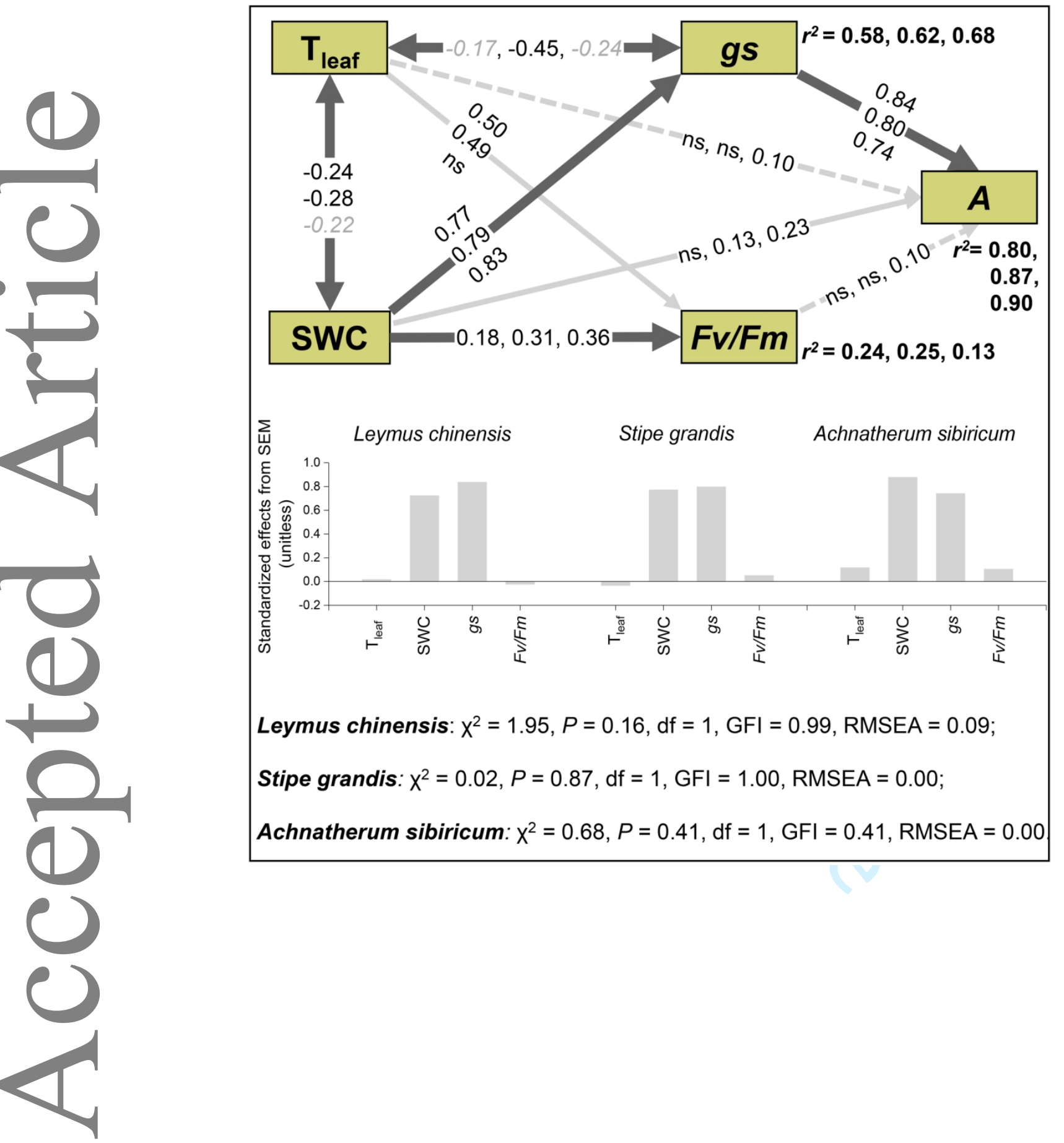

This article is protected by copyright. All rights reserved. 


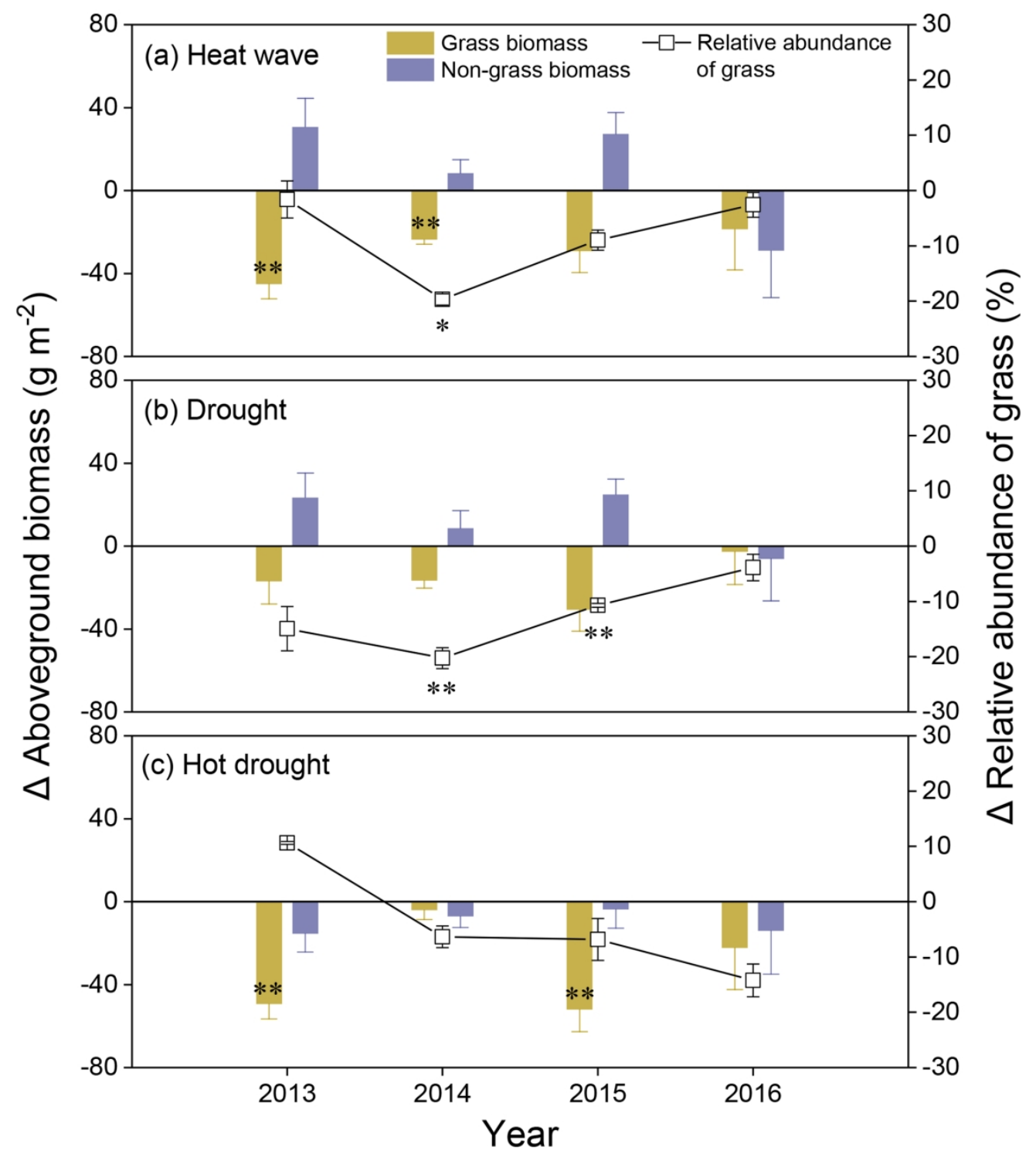

This article is protected by copyright. All rights reserved. 


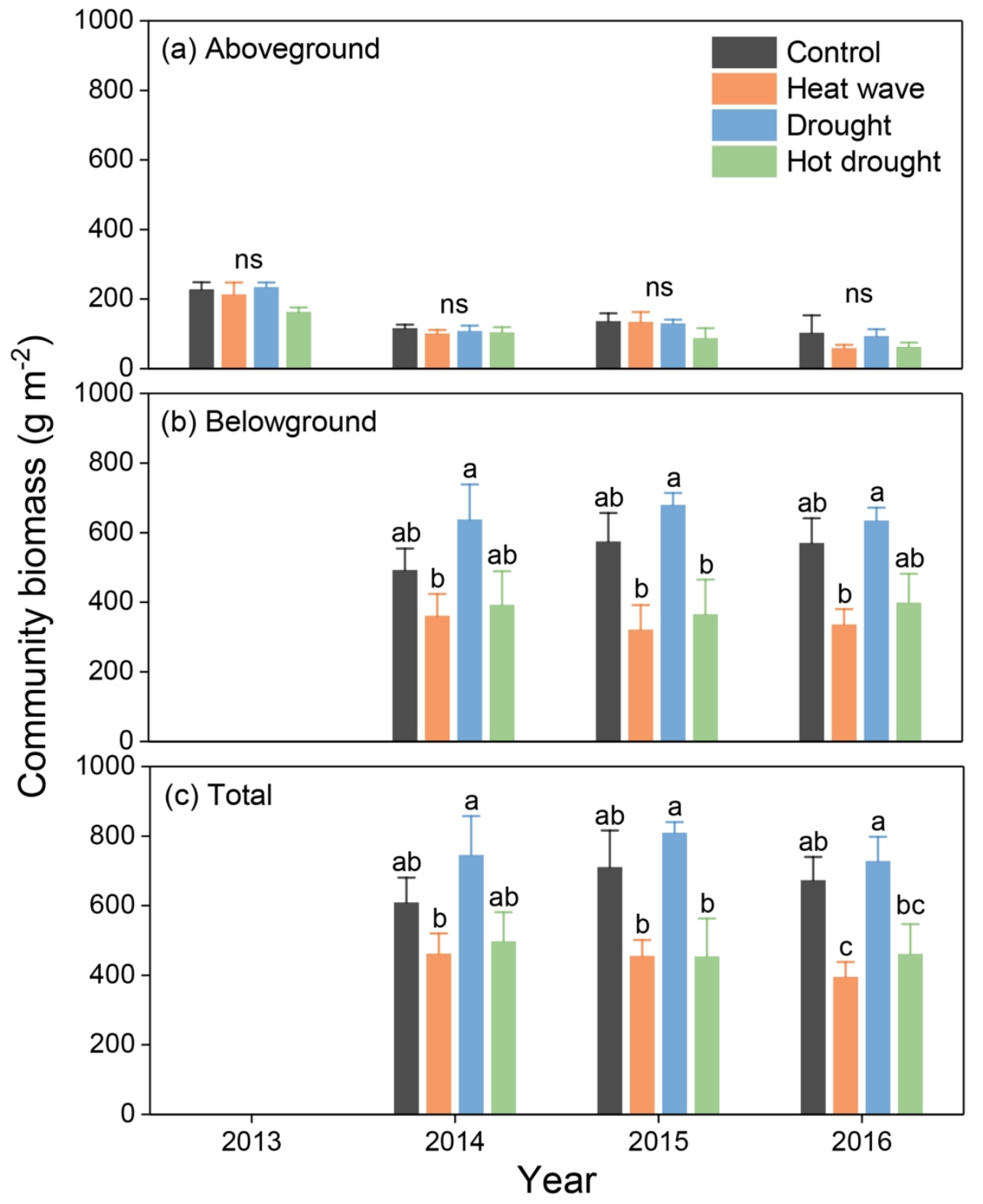

This article is protected by copyright. All rights reserved. 


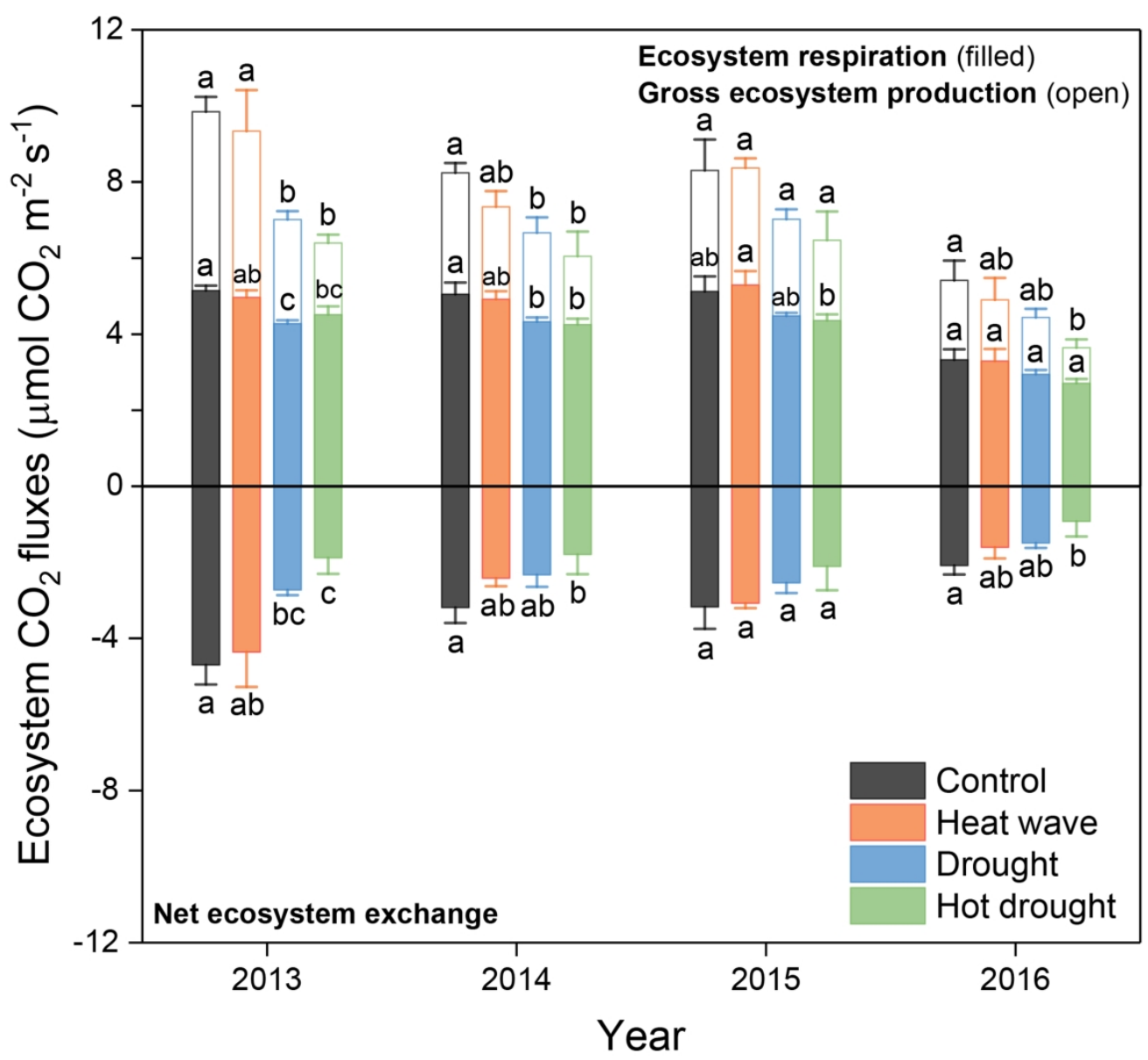

This article is protected by copyright. All rights reserved. 


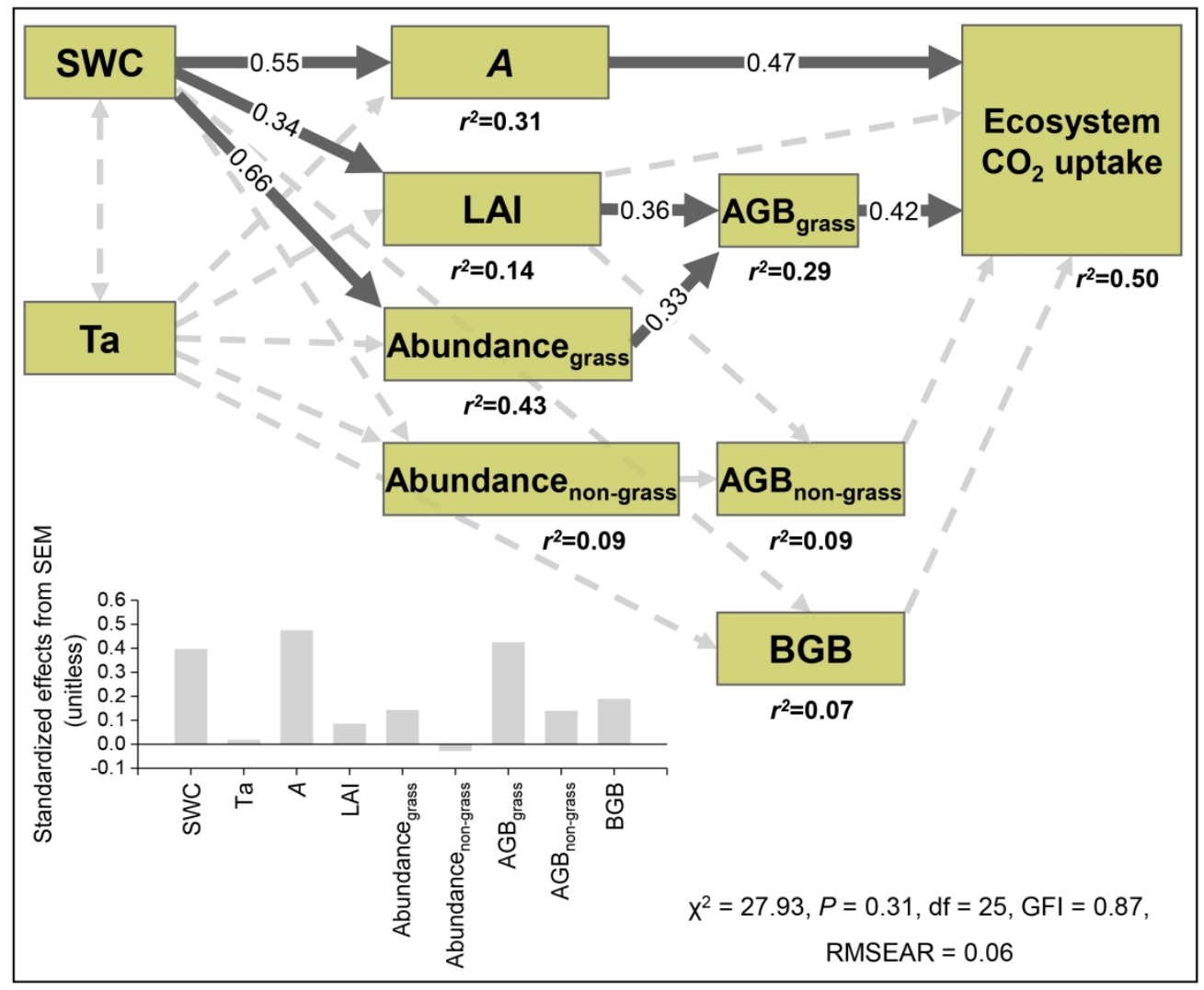

This article is protected by copyright. All rights reserved. 